\title{
MicroRNA profiling of the pig periaqueductal grey (PAG) region reveals candidates potentially related to sex- dependent differences
}

\author{
Klaudia Pawlina-Tyszko ${ }^{1 *}$ (D, Maria Oczkowicz ${ }^{1}$, Artur Gurgul1,2, Tomasz Szmatoła ${ }^{1,2}$ and
} Monika Bugno-Poniewierska ${ }^{3}$

\begin{abstract}
Background: MicroRNAs indirectly orchestrate myriads of essential biological processes. A wide diversity of miRNAs of the neurodevelopmental importance characterizes the brain tissue, which, however, exhibits region-specific miRNA profile differences. One of the most conservative regions of the brain is periaqueductal grey (PAG) playing vital roles in significant functions of this organ, also those observed to be sex-influenced. The domestic pig is an important livestock species but is also believed to be an excellent human model. This is of particular importance for neurological research because of the similarity of pig and human brains as well as difficult access to human samples. However, the pig PAG profile has not been characterized so far. Moreover, molecular bases of sex differences connected with brain functioning, including miRNA expression profiles, have not been fully deciphered yet.

Methods: Thus, in this study, we applied next-generation sequencing to characterize pig PAG expressed microRNAs. Furthermore, we performed differential expression analysis between females and males to identify changes of the miRNA profile and reveal candidates underlying sex-related differences.

Results: As a result, known brain-enriched, and new miRNAs which will expand the available profile, were identified. The downstream analysis revealed 38 miRNAs being differentially expressed (DE) between female and male samples. Subsequent pathway analysis showed that they enrich processes vital for neuron growth and functioning, such as long-term depression and axon guidance. Among the identified sex-influenced miRNAs were also those associated with the PAG physiology and diseases related to this region.

Conclusions: The obtained results broaden the knowledge on the porcine PAG miRNAome, along with its dynamism reflected in different isomiR signatures. Moreover, they indicate possible mechanisms associated with sex-influenced differences mediated via miRNAs in the PAG functioning. They also provide candidate miRNAs for further research concerning, i.e., sex-related bases of physiological and pathological processes occurring in the nervous system.
\end{abstract}

Keywords: microRNAs, PAG, Brain, NGS, Pig

* Correspondence: klaudia.pawlina@izoo.krakow.pl

'Department of Animal Molecular Biology, National Research Institute of Animal Production, Krakowska 1, 32-083, Balice, Kraków, Poland

Full list of author information is available at the end of the article

C The Author(s). 2020 Open Access This article is licensed under a Creative Commons Attribution 4.0 International License, which permits use, sharing, adaptation, distribution and reproduction in any medium or format, as long as you give appropriate credit to the original author(s) and the source, provide a link to the Creative Commons licence, and indicate if changes were made. The images or other third party material in this article are included in the article's Creative Commons licence, unless indicated otherwise in a credit line to the material. If material is not included in the article's Creative Commons licence and your intended use is not permitted by statutory regulation or exceeds the permitted use, you will need to obtain permission directly from the copyright holder. To view a copy of this licence, visit http://creativecommons.org/licenses/by/4.0/. The Creative Commons Public Domain Dedication waiver (http://creativecommons.org/publicdomain/zero/1.0/) applies to the data made available in this article, unless otherwise stated in a credit line to the data. 


\section{Background}

The domestic pig (Sus scrofa) is an important animal not only for livestock production but also from the biomedical point of view as an alternate, large mammal model organism for the human [1-3]. This especially applies to neurological research because of the similarity of brain development (the growth pattern and the extent of peak brain growth at the time of birth), anatomy (i.e., gyral pattern and distribution of gray and white matter), and size between pigs and humans [4]. Thus, the pig is considered to be of great potential for broadening the knowledge of general neuronal and behavioral processes, as a subject of central nervous system (CNS) research, including neuroanatomy, neurobiology, and cognitive neuroscience [4]. It is also postulated for validation as an animal model for neurological and neuropsychiatric diseases such as schizophrenia and Alzheimer's disease. So far, it has been used in imaging studies as an experimental model of traumatic brain injury, Parkinson's disease and stroke, as well as to investigate serotonin and dopamine systems [4].

The brain is the central organ of the nervous system which is composed of many specialized structures and regions. The periaqueductal gray matter (PAG) is one of the mostly evolutionary conserved components of the brain. It is the central gray matter of the midbrain, to a large extent analogous to the gray matter of the spinal cord. It modulates various important functions including autonomic [5, 6], behavioral [7], pain [8], as well as defensive, reproductive, and maternal behavior [9, 10]. Moreover, it may be affected in many disorders, such as migraine [11], Wernicke's encephalopathy [12], multiple sclerosis (MS) [13], and stroke [14, 15].

The brain, as a complex body organ, is characterized by a large diversity of miRNAs [16]. MicroRNAs are highly conserved, short ( 21-23 nt) non-coding RNAs which orchestrate gene expression at the posttranscriptional level by binding to their targets-mRNAs [17]. miRNAs have been implicated to play crucial roles in most biological processes, not only in healthy tissues [18-21] but also in those undergoing pathological changes such as neoplastic transformation [22-24]. Therefore, microRNAs are also successfully used as biomarkers for diagnosis and prognosis [25-28]. They have also been identified to be engaged in the regulation of vital neuronal processes during neurogenesis and neuron functioning [29], as well as brain development, which is shown to undergo intensive changes of miRNA expression $[30,31]$.

To date, the miRNA expression profile of the pig brain tissue, namely cortex and cerebellum, has been identified by Podolska and colleagues [32].Nevertheless, brain regions are established to differ in gene expression [33] and miRNA profiles [34], and some of them can exert area-specific functions [34]. Moreover, the pig, with its 457 mature miRNA sequences deposited in miRBase Release 22.1, still stays behind the human (2654 mature miRNAs). Thus, in this study, we attempted to comprehensively characterize the miRNAome profile of the porcine PAG and, at the same time, broaden the whole pig miRNA profile and PAG profile. To this end, we applied next-generation sequencing, which allows for the detection of novel miRNA sequences as well as isomiR variants.

Additionally, the PAG region has been reported to play roles in many different neurodiseases and brain functions which are known to be sex-influenced, such as maternal behavior, pain [35, 36], and stroke [37]. Hence, we hypothesized that the PAG-expressed miRNAs may exhibit different expression profiles between sexes and, as a result, may be involved in sex-related differences. Therefore, we identified microRNAs differentially expressed between male and female samples, and biological pathways which they regulate, to pinpoint possible miRNA-involved mechanisms underlying sex differences and elucidate miRNA potential engagement.

Summing up, taking into account the important role that the PAG plays in the functioning of the brain, the aim of our work was to characterize its miRNA profile, including the identification of new miRNAs expressed in this region, as well as shed some light on the potential roles of miRNAs in shaping sex specific differences. It will not only broaden our knowledge on miRNAs and their significance in mechanisms occurring in the PAG, also those sex-related, but also provide data for further interspecies comparative studies, especially in humans, since the availability of brain samples is limited.

\section{Methods}

\section{Research material}

Periaqeductal grey samples were collected from 21 pigs maintained and slaughtered at $100 \mathrm{~kg}$ of weight at the Pig Testing Station of the National Research Institute of Animal Production in Pawłowice under the same housing and feeding conditions. The samples were frozen in liquid nitrogen immediately after collection, and stored at $-80{ }^{\circ} \mathrm{C}$ until RNA isolation. The animals (6 males and 15 females) belonged to the Polish 990 synthetic line of pigs, which is a hybrid of several breeds (Large White, Belgium Landrace, Duroc, German Landrace, Walsh Landrace, and Hampshire). The performed research did not require the approval of Animal Ethics Committee since meat from slaughtered animals is standard intended for consumption.

\section{MicroRNA sequencing}

Total RNA extracted with the use of Direct-zol RNA Mini Prep kit (Zymo Research) according to the protocol 
was further subjected to the quantity and quality controls using a NanoDrop 2000 spectrophotometer (Thermo Fisher Scientific), and a TapeStation 2200 instrument (Agilent), respectively. NEBNext Multiplex Small RNA Library Prep Set for Illumina (New England Biolabs) was used to prepare miRNA libraries. This protocol starts with the 3 ' adaptor ligation, followed by hybridization with the Reverse Transcription Primer and ligation with the $5^{\prime}$ adaptor. Obtained products were reverse transcribed, and PCR amplified, including 12 different indexed primers to allow multiplexing of the samples. The libraries were then subjected to sizeselection with Novex 6\% TBE PAGE gel (Invitrogen) electrophoresis, followed by ethanol (POCH) purification and precipitation. The concentration of the obtained libraries was measured with a Qubit 2.0 Fluorometer (Thermo Fisher Scientific), while a 2200 TapeStation instrument (Agilent) was used to assess their size. The libraries mixed with the PhiX control library (Illumina) were clustered on an Illumina Flowcell_v3 in a cBot cluster station and then sequenced on HiScan SQ (Illumina) system according to the manufacturer protocol.

\section{Bioinformatics analysis}

The obtained raw reads were subjected to the following processing: conversion to FastQ files, demultiplexing with the use of the bcl2fastq software (Illumina), and quality control using the FastQC software [38]. Then, the obtained sequences were analyzed using UEA sRNA Workbench V4.6 [39] to identify known and potentially novel miRNA sequences. First, 3' adaptor sequences were trimmed off and tRNA and rRNA sequences were discarded from the data. miRNA identification with the miRCat tool was performed with the default animal parameters except for minimum abundance (6 reads), minimum length (17 $\mathrm{nt}$ ), and maximum length (25 nt) [40]. The identification was performed on the basis of the Sus scrofa genome (assembly Sscrofa 10.2) and miRBase v22.1 [41, 42]. Predicted candidate microRNA precursors were searched in the RNAcentral database v14 [43] to exclude those belonging to other non-coding RNA species. The remaining miRNA sequences were subjected to the identification of isomiRs that is microRNA length and sequence variants, using the isomiRSEA software [44] and the default settings. Finally, detected miRNAs were analyzed using the DESeq2 software [45] to identify those differentially expressed between females and males. Since resultant miRNAs have false discovery rate $(\mathrm{FDR})>0.05$, we chose statistically significant microRNAs differentially expressed at nominal $p$ value $\leq 0.01$ for further analyses. The most significant $(p$ value $\leq 0.005)$ miRNAs were visualized with the pheatmap v1.0.12 package [46] using the $R$ package v3.6.1 [47].
miRNA-target gene interaction networks and enriched biological pathways

Interaction networks of the detected differentially expressed miRNAs and their database-deposited target genes were illustrated with the use of the miRNet 2.0 online platform $[48,49]$. To this end, we chose "miRNAs" from the available options. The analysis was carried out with the default settings, except for a filter "Degree cutoff" which was set to 4.0, in order to increase the legibility of obtained networks and visualize the most important interactions.

The mirPath v.3 DIANA Tools web application [50] was used to determine biological processes enriched by the identified differentially expressed microRNAs (DE miRNAs) (females vs. males). The analysis was carried out employing experimentally validated target genes deposited in TarBase v7.0, as well as KEGG Pathway Database and Gene Ontology (GO) as reference databases.

\section{qPCR validation}

Eleven microRNAs were chosen for the validation with the use of reverse transcription quantitative polymerase chain reaction (RT-qPCR) method. TaqMan Advanced miRNA cDNA Synthesis Kit (Thermo Fisher Scientific) was used to perform reverse transcription, while TaqMan Fast Advanced Master Mix (Thermo Fisher Scientific) and commercially available TaqMan microRNA Advanced Assays (Thermo Fisher Scientific) to run qPCR reactions in triplicates including non-template control (NTC) for each microRNA assay. qPCR reaction mix for one sample contained $10 \mu \mathrm{l}$ TaqMan Fast Advanced Master Mix (2X), $1 \mu$ l TaqMan Advanced miRNA Assay (20x), $4 \mu \mathrm{l}$ RNase-free water, and $5 \mu \mathrm{l} \mathrm{di-}$ luted $(1: 10) \mathrm{cDNA}$ template. All reactions were carried out according to the standard protocols on QuantStudio 7 Flex Real-Time PCR System (Thermo Fisher Scientific). miRNAs with the most stable expression profiles as specified by the NormFinder software [51] were selected as reference controls (miR-100-5p, miR-499a-5p). Relative expression levels were computed applying $\Delta \Delta \mathrm{Ct}$ method including reaction efficiency $E$ [52] calculated with the use of the standard curve method.

\section{Results}

\section{miRNAome profile of the PAG region}

We conducted next-generation sequencing to characterize the miRNAome profile of the pig PAG area of the brain. As a result, from 3,567,080 to 6,033,979 raw sequences in individual samples were obtained. Subsequent filtering resulted in on average 3,311,434 sequences, which were further mapped to the Sus scrofa genome and miRBase 22.1. This allowed the identification of 237 unique known microRNAs, including 53 microRNAs* from the other strand, and 286 potentially 
new miRNA sequences (Supplementary File 1). The most predominantly expressed miRNAs were 22nt long. The miRNA profiling results were submitted to the NCBI GEO database and the following GEO accession number was assigned: GSE148302.

\section{Females vs. males differentially expressed microRNAs}

Next, we performed differential expression analysis using the DESeq2 algorithm, which revealed 38 statistically significantly differentially expressed microRNAs ( $p$ value $\leq 0.01$ ) in the female samples with reference to the male samples. Among them, 12 miRNAs were underexpressed and consisted of 29 isomiRs, whereas 26 microRNAs were overexpressed and included 84 isomiRs. All DE isomiR sequences originating from one microRNA showed the same direction of expression changes. The number of DE isomiRs belonging to one microRNA ranged from one (e.g., ssc-miR-150) to 17 isomiRs for ssc-miR-92b3 p. DE analysis details are present in Supplementary File 2 , and the most significant ( $p$ value $\leq 0.005$ ) differentially expressed microRNAs and their isomiRs are illustrated in Fig. 1.

\section{Pathways enriched by sex differentially expressed microRNAs}

The visualization of interaction networks of DE microRNAs and their target genes is presented in Figs. 2 and 3. The network, after degree filtering, embraces vast numbers of target genes (230) and long non-coding RNAs (66). It includes the following genes: ZNF148, MAP2K1, IGFR1, SERPINE1, TMEM30A, IL1A, NOTCH1, FOXN2, and many others. Whereas lncRNAs are represented by XIST, DLEU1, KCNQ1OT1, NEAT1, HELLPAR, and MALAT1.

Moreover, we analyzed identified differentially expressed microRNAs (females vs. males) to elucidate their functions in the pig PAG region, with particular emphasis on a potential sex impact. As a result, numerous enriched KEGG pathways (Supplementary File 3) and GO terms (Supplementary File 4) were identified, encompassing a variety of biological processes. The most interesting over-represented KEGG pathways were fatty acid metabolism (hsa01212), estrogen signaling pathway (hsa04915), oocyte meiosis (hsa04114), endometrial cancer (hsa05213), progesterone-mediated oocyte maturation (hsa04914), prolactin signaling pathway (hsa04917) (Fig. 4), long-term depression (hsa04730) (Fig. 5), steroid biosynthesis (hsa00100), and axon guidance (hsa04360) (Fig. 6) (Table 1). The enriched significant GO terms included response to stress (GO:0006950), enzyme regulator activity (GO:0030234), immune system process (GO: 0002376), catabolic process (GO:0009056), generation of precursor metabolites and energy (GO:0006091), and transcription factor binding (GO:0008134) (Table 2). All identified GO terms and engaged miRNAs are shown in Fig. 7.

\section{qPCR validation}

The validation of miRNA sequencing results showed a high and significant Spearman correlation between nextgeneration sequencing (NGS) and qPCR for most of the analyzed miRNAs (from 0.56 to 0.95 ) (Table 3). Correlation coefficients were not significant for miR-23a-3p, $-103 a-3 p,-339-5 p$, but the direction of expression changes obtained by these two methods was the same.

\section{Discussion}

MicroRNAs have emerged as key regulators of a plethora of biological processes, including those occurring in the central nervous system. Accumulating evidence on their vital roles in different aspects of neurodevelopment and functioning provides resources to elucidate the physiology and pathophysiology of this complex system. The implementation of high throughput technologies allows further, deeper insight into the subject and facilitates characterization of this still unraveled and incomplete picture of miRNA repertoire and its regulatory influence.

miRNA profiling reveals inter-species conservative nature and ubiquitous expression of ssc-miR-9, -26a, and $-99 a-5 p$ in different brain regions

To date, an approach was made to identify miRNAdependent regulatory mechanisms related to brain development ontogenesis in pigs. Using the microarray technology and qRT-PCR, Podolska and colleagues [32] determined miRNA expression levels in the developing pig brain. Noteworthy, almost half of the known miRNAs detected in our study overlaps with their results, which suggests that they may be pig, brain-ubiquitous miRNAs. The differences of miRNA profiles obtained by our research teams may stem from different methods applied (microarrays vs. NGS), developmental stages (fetuses and piglets vs. adult pigs), brain regions (cortex and cerebellum vs. PAG), and available at the time reference miRNAs (miRBase 15.0 vs. 22.1). Likewise, $18 \mathrm{miR}$ NAs were common for this study and human brain miRNA profiling studies which established the vital roles of miRs in a variety of neuron-occurring processes, and in disruptions of neuronal functions [53]. This stays in agreement with the nature of the examined tissue and, as such, confirms the obtained miRNA profile results.

What is more, numerous isomiRs (sequence and length variants) were detected, also those differing in the $5^{\prime}$ end sequences comprising alternative seed sequences (Fig. 1, Supplementary File 2). This implies that they can undergo target gene switching, and, as a result, influence different biological pathways [54, 55], which further can have a major impact on the whole tissue functioning. 


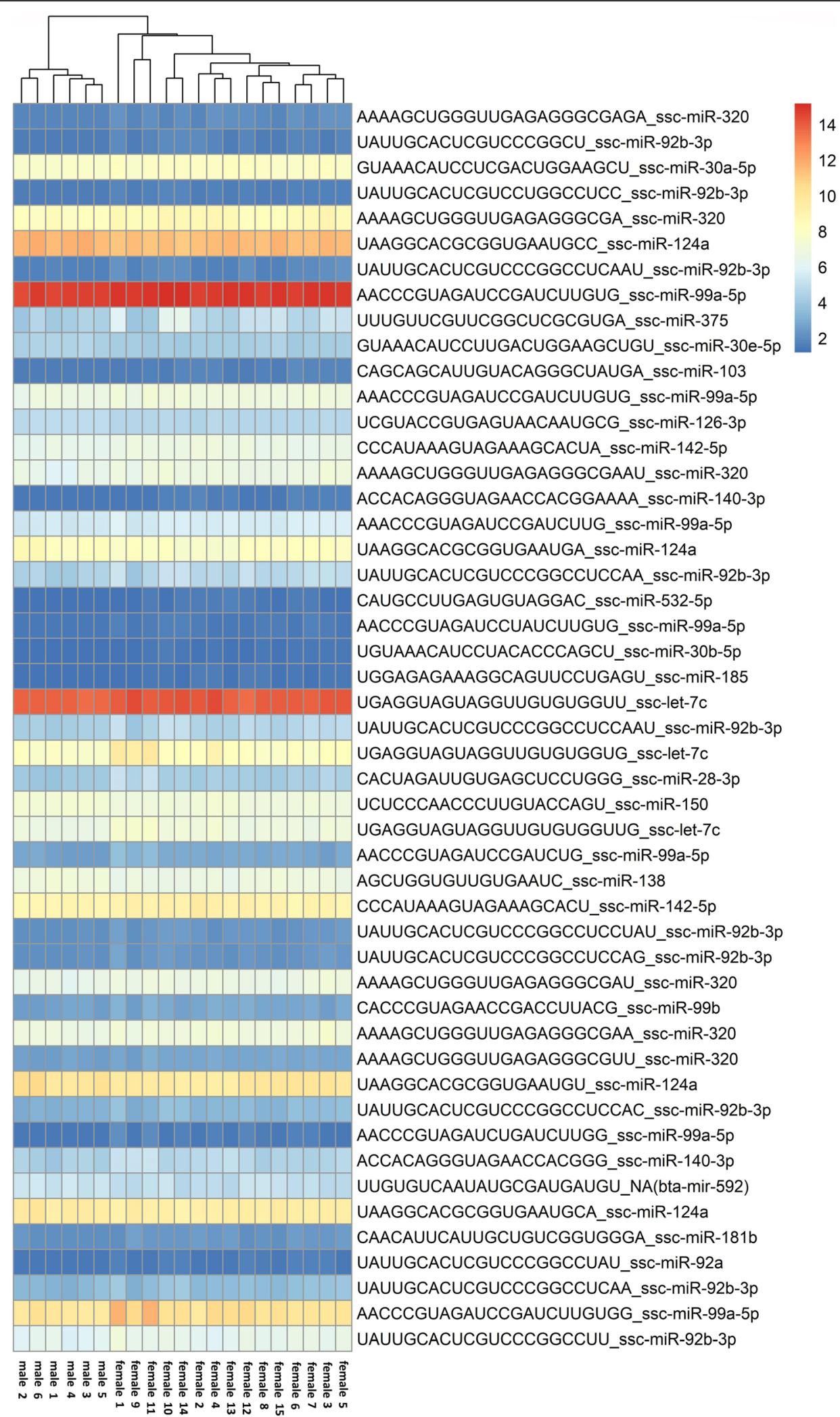

Fig. 1 The expression pattern Heat Map. The Heat Map depicts the most significant ( $p$ value $\leq 0.005$ ) differentially expressed miRNAs and their isomiRs (females vs males; males constitute the reference group) (R Package pheatmap) 


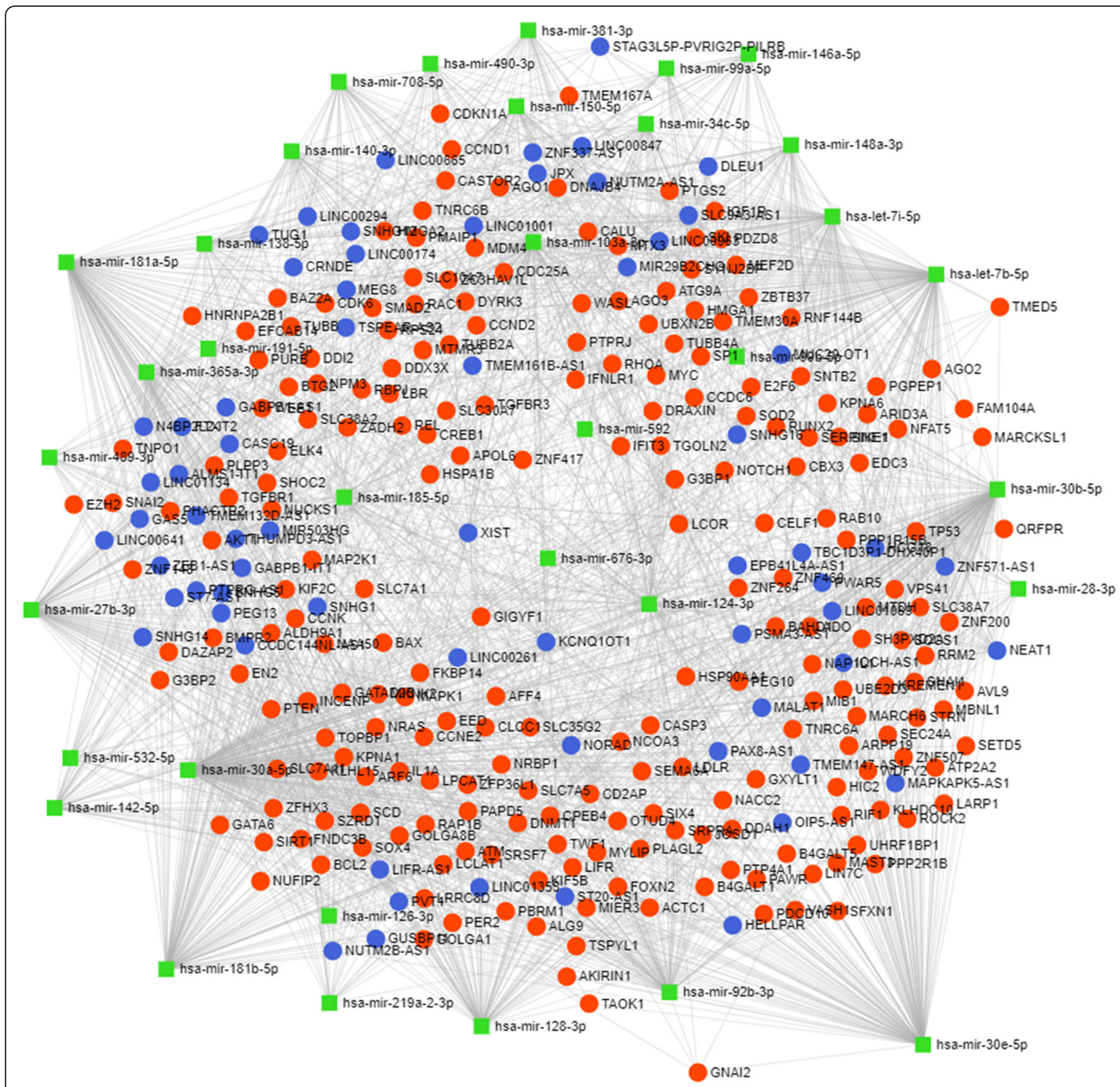

Fig. 2 MiRNA interaction network. Global interaction network between the identified differentially expressed miRNAs (females vs. males), and predicted genes as well as long non-coding RNAs, which they target (miRNet web application). Green squares stand for DE microRNAs, red circles denote target genes, while blue circles stand for IncRNAs

The most abundantly expressed in the examined in this study pig PAG samples were ssc-miR-9, -26a, and -99a-5p (Supplementary File 1). Of those, miR-9 is classified as a NeurimmiR that is a brain-specific microRNA involved in the mediation of the immune system functioning [56], while miR-26a and -99a are brain-enriched miRs $[53,57]$. They were also identified by Podolska and colleagues [32] in the developing pig brain (cortex and cerebellum). These miRNAs were shown to play important roles in neuronal functioning in different species, such as memory, synaptic plasticity, and neuroinflammation $[56,58]$. Their detection in the present study indicates their inter-species conservative nature and ubiquitous expression in different brain regions. However, their exact significance in the PAG physiology remains to be elucidated.

Female vs. male differential expression analysis identifies candidate miRNAs associated with neurological and psychiatric disorders as well as pain modulation

The performed analysis of miRNAs differentially expressed in females in comparison to males revealed 38 microRNAs (Supplementary File 2), of which five (miR- 


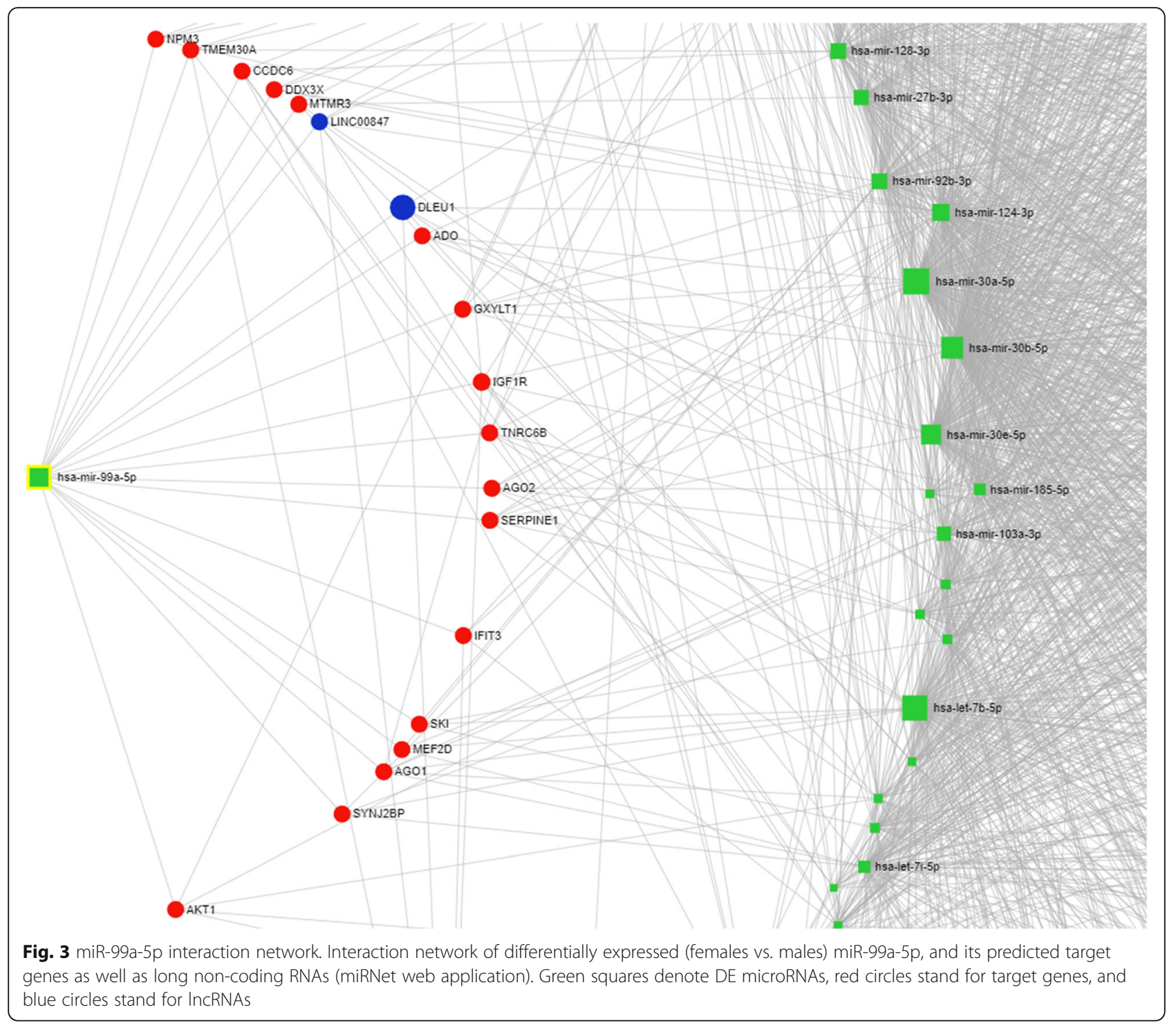

146b-5p, -126-3p, -103a-3p, -181a-5p, -181b-5p) overlap with those detected by Meder and colleagues [59] in human peripheral blood as influenced by sex. Furthermore, Munoz-Culla and colleagues [60] profiled miRNAomes of peripheral blood leukocytes of patients with relapses and remission of multiple sclerosis, and revealed sexdependent differences. Among miRNAs found as differentially expressed in female but not in male remission patients were miR-27b-3p, 30a-5p, -30e-5p, and -148a$3 p$, which were also established in this study as differentially expressed (Fig. 1, Supplementary File 2). It should be noted that our studies comprised different species, tissues, methodological approaches, sample numbers, and last but not least different miRBase releases, which may explain those few common miRNAs, which, however, are still of the importance because they may constitute the most conservative miRNAs and confirm the obtained results.

miR-99a-5p was not only determined in our study as abundantly expressed in the PAG but was also shown to be upregulated in the female samples in comparison to the male samples (Fig. 1, Supplementary File 2). Considering the fact that the expression of this miRNA is stroke-influenced, these results may suggest that this miR may be one of the elements of the regulatory network associated with different susceptibility of females and males to ischemic stroke [37]. Other miRNAs identified as sex differentially expressed in our study (miR124, -148a, -let-7i, -320d, -320e, -30a, -126, -219) may also constitute components of this network because of the fact that they were determined as stroke-dependent microRNAs as well [61]. 


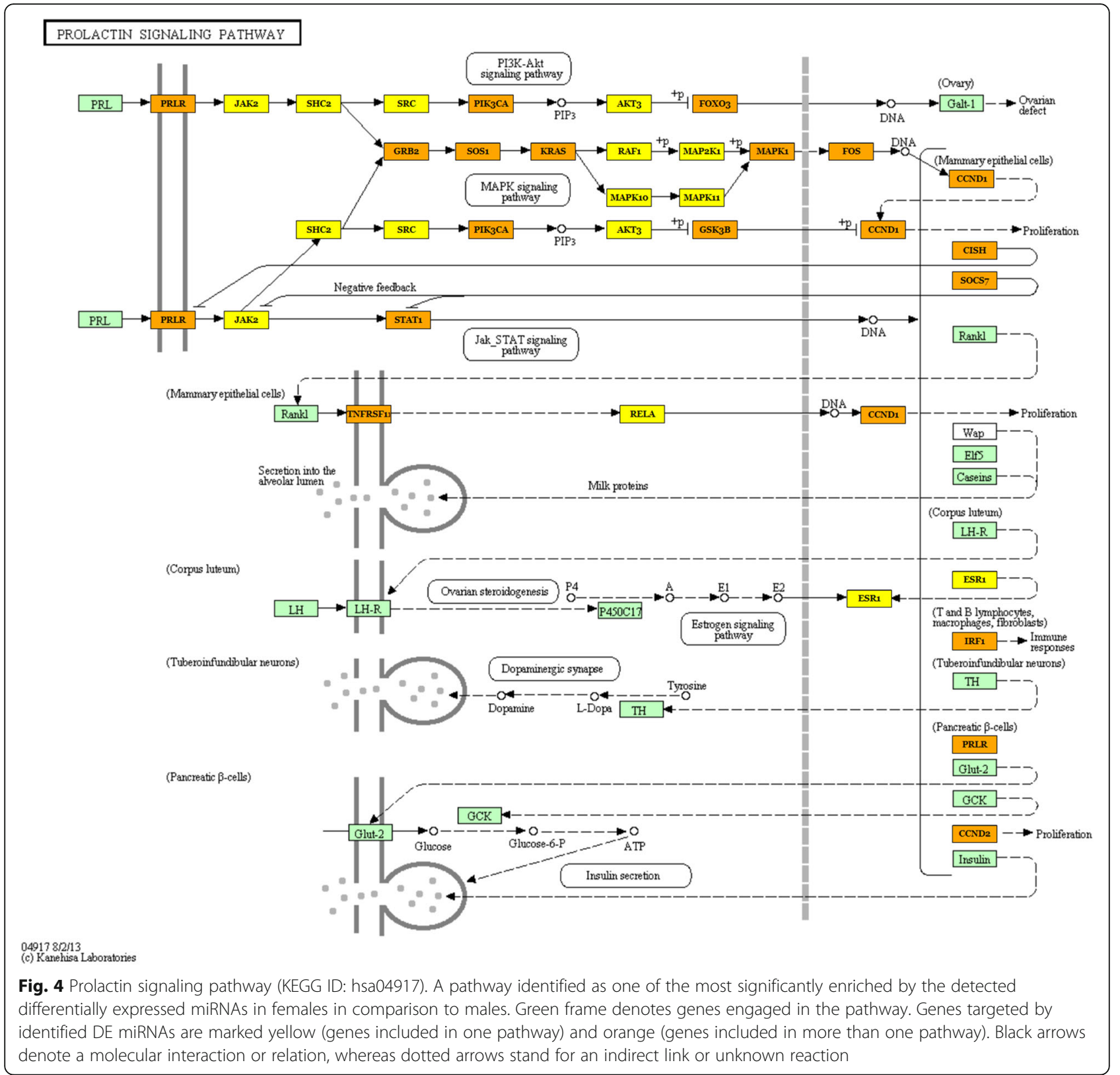

miR-99a-5p poses an interesting subject of further research especially since the miRNet miRNA-target interaction analysis (Figs. 2 and 3 ) showed that it might exert gene regulatory influence on a handful of central nervous system crucial genes. For example, high expression levels of DEAD-box helicase 3 X-linked (DDX3X) encoding adenosine triphosphate (ATP)-dependent RNA helicase are correlated with poor survival outcome in human gliomas [62]. Furthermore, insulin-like growth factor-1 receptor (IGF1R) was shown to take part in the regulation of cortical neuronal migration, axon formation and polarity of those neurons [63], and brain development in a region-specific manner [64]. Argonaute 1 (AGO1) and Argonaute 2 (AGO2) comprise another worth attention targets since they code for proteins essential for proper RNA-induced silencing complexes (RISC) assembly and function, and, as a result, determine global miRNA abundance. Of note, disrupted RISC assembly within CNS was observed during autoimmune demyelination [65]. Another gene, serpin family E member 1 (SERPINE1), was established as a key regulator in glioblastoma dispersal [66] and may constitute a promising therapeutic target in Alzheimer's disease [67]. Whereas myocyte enhancer factor 2D (MEF2D) gene belongs to the MEF2 family of transcription factors, which was shown to play important roles during brain development and function. Moreover, these transcription factors were suggested to exert a complex and profound 
LONG-TERM DEPRESSION

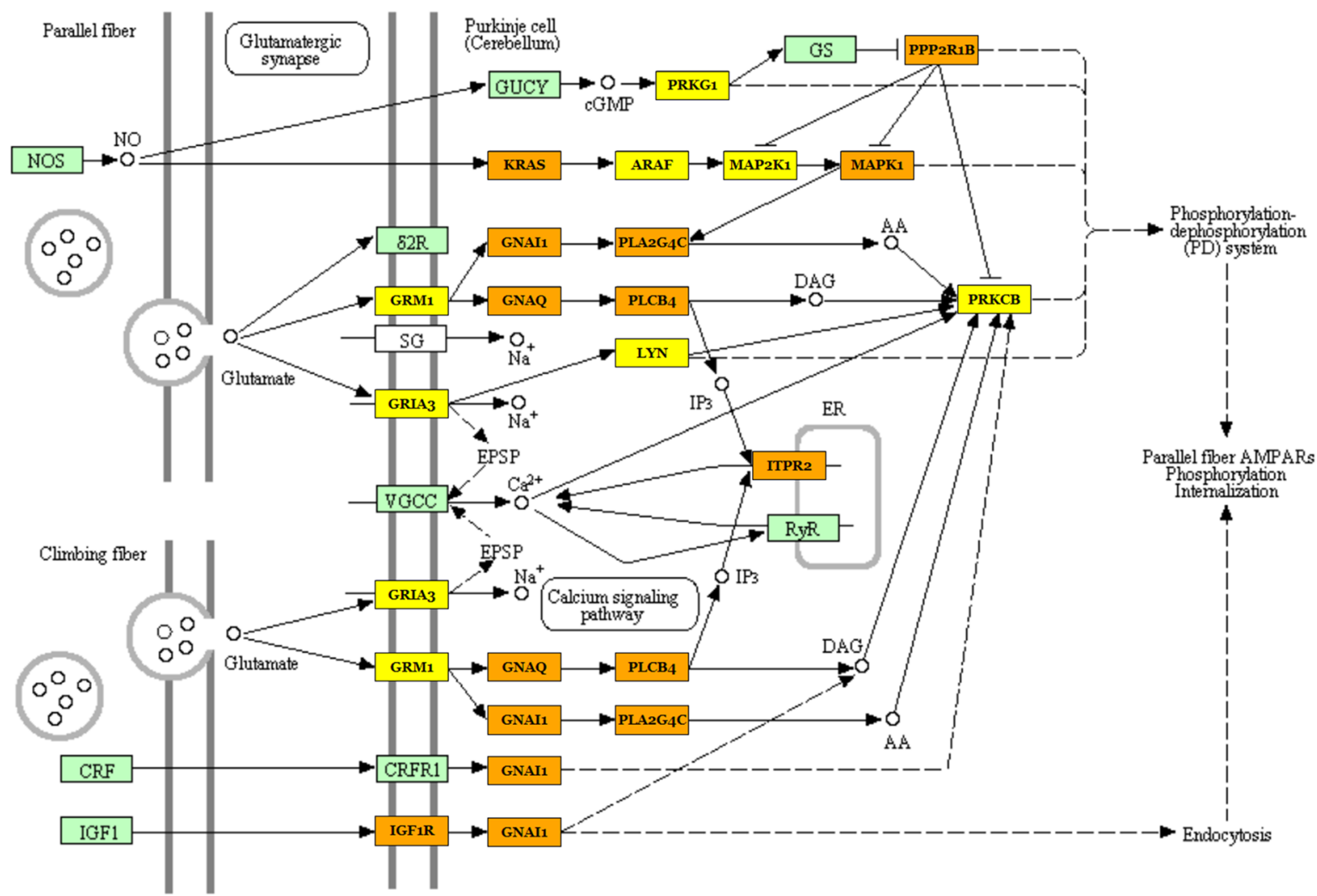

$047305 / 1113$

(c) Kanehisa Laboratories

Fig. 5 Long-term depression (KEGG ID: hsa04730). One of the most significantly enriched pathways by the detected differentially expressed between females and males microRNAs. Green frame stands for genes engaged in the pathway. Genes targeted by detected DE microRNAs are marked yellow (genes included in one pathway) and orange (genes included in more than one pathway). Black arrows stand for a molecular interaction or relation, while dotted arrows stand for an indirect link or unknown reaction

influence on memory formation [68]. The MEF2 family was also emphasized as a risk factor for neuronal developmental disorders, psychiatric disorders such as schizophrenia, and mental illnesses such as autism [69].

Interestingly, other identified herein DE miRNAs in females in comparison to males were also shown to have altered expression levels in psychiatric disorders pathogenesis, namely miR-219, $-181 \mathrm{~b},-124,-320,-128$, and30a [70]. Notably, two research teams investigating changes of miRNA profiles in schizophrenia revealed numerous dysregulated miRNAs, of which miR-30b, -92 , -30a-5p [71] and miR-128, -138-, 148a, -150, -27b, -28, $-381,-489,-99 a,-181 a,-181 b$ [72] were also found as differentially expressed (females vs. males) in our study (Fig. 1, Supplementary File 2). This seems to provide a valuable stimulus for further extended studies since the PAG was hypothesized to play roles in schizophrenia as a structure mediating basic emotions and primordial self-consciousness $[73,74]$. A brief overview of differentially expressed miRNAs identified in this study and various brain diseases is presented in Table 4.

Additionally, schizophrenia is also characterized by sexdriven differences which are reflected in the age of onset, symptoms, and response to treatment [87-90]. The exact pathogenesis of these differences remains vague and may embrace a variety of genetic and environmental factors; nevertheless, identified herein sex differentially expressed miRNAs emerge as candidates for more extensive research, especially since they coincide with biological pathways relevant to neuron functioning, such as PI3K-Akt signaling pathway (Supplementary file 3).

One of the most intensively studied roles of the PAG is the modulation of pain $[8,91]$, which was established to differ substantially between males and females $[35,36]$. Accumulating evidence suggests that this sex differential pain sensitivity stems from not only neuroanatomical features but also the influence of sex hormones, and the degree of proinflammatory immune response, which is in 


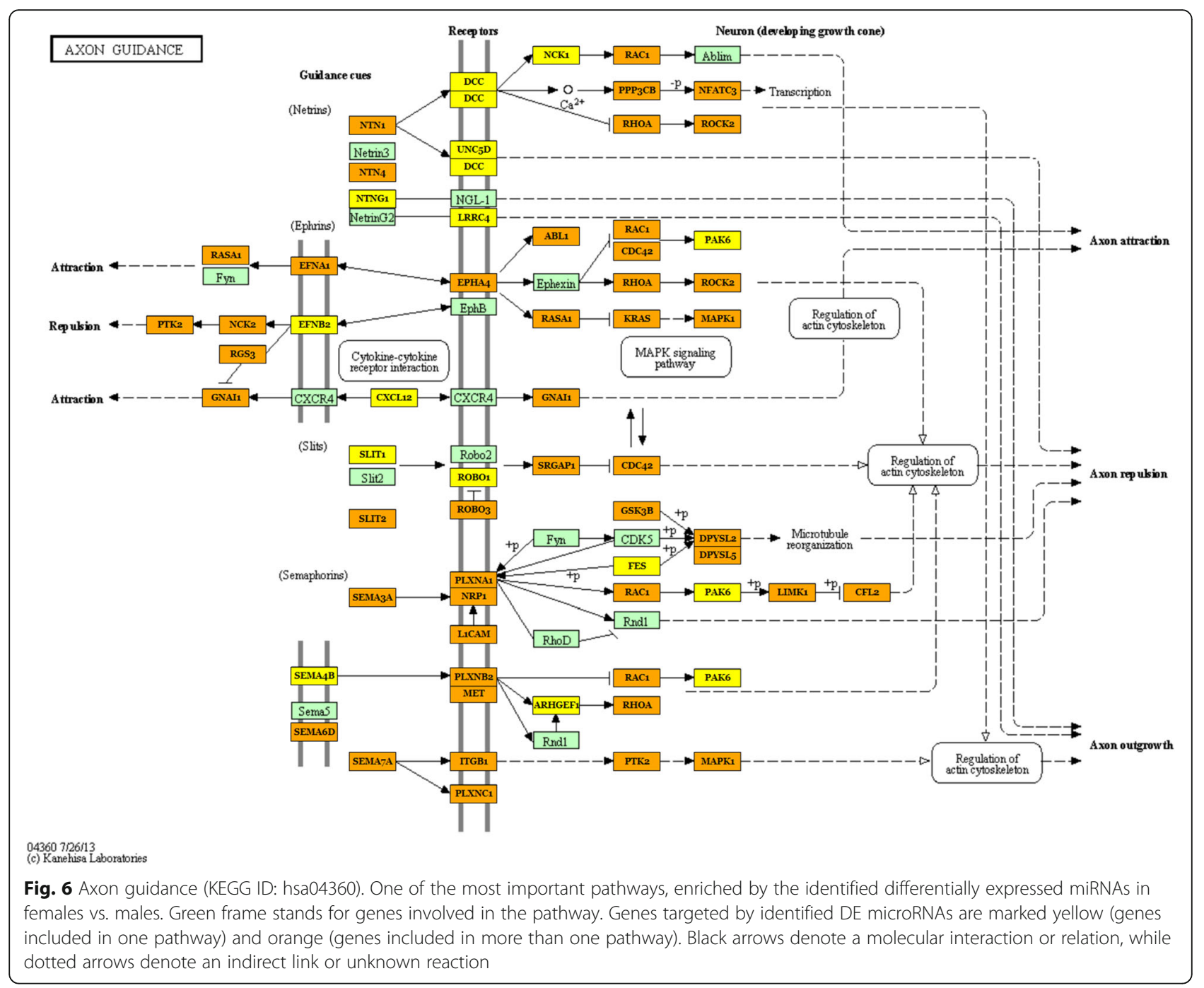

line with estrogen signaling pathway (Table 1) and immune system process (Table 2, Fig. 7) identified in this study as enriched by miRNAs differentially expressed between males and females.

Furthermore, numerous studies allowed characterization of miRNAome signatures of patients suffering from different types of pain and identification of miRNAs with potential to serve as pain subtype and intensity biomarkers [92-100]. A handful of those miRNAs was also identified in this study as differentially expressed in the PAG region between females and males (Supplementary file 2). These common miRNAs embrace miR-126-3p which was detected in chronic musculoskeletal pain [99], migraine [98], and complex regional pain syndrome [92] as well as miR-320a identified in chronic musculoskeletal pain [99], complex regional pain syndrome [92], persistent axial musculoskeletal pain [96], and fibromyalgia suffering patients [93]. Moreover, Linnstaedt and colleagues suggested the existence of sex influence in the case of miR-320a [96]. We also detected miR-181a and
$-142-5 p$ which were differentially expressed in complex regional pain syndrome [92] and migraine [94, 95], while miR150-5p was reported in chronic musculoskeletal pain [99]. Two more miRNAs identified in complex regional pain syndrome (let-7c, miR-185) [92] and fibromyalgia suffering patients (miR-103a-3p, miR-30b-5p) [93] were also DE in this study. Furthermore, Leinders and colleagues reported miR146a-5p to be altered in peripheral neuropathies [97], while Tavares-Ferreira's team identified altered expression of miR138 in lingual nerve neuromas [100]. When it comes to profiled migraine miRNAs, the differential expression of miR27b [94] and miR-34c, -124-3p, -375, and -532-5p [95] was also shown in our study in females vs. males.

These pain-associated miRNAs may constitute interesting subjects of additional research focused on deciphering the meaning and exact roles of microRNAs in sex-driven pain differences; especially since they were identified in this study as overrepresented in the aforementioned estrogen signaling pathway and immune 
Table 1 Significant KEGG pathways enriched in the identified miRNAs differentially expressed in females vs. males

\begin{tabular}{|c|c|c|c|c|c|}
\hline KEGG pathway & $\begin{array}{l}\text { Number } \\
\text { of genes }\end{array}$ & Examples of genes & $\begin{array}{l}\text { Number } \\
\text { of miRNAs }\end{array}$ & Examples of miRNAs & $p$ value \\
\hline $\begin{array}{l}\text { Fatty acid metabolism } \\
\text { (hsa01212) }\end{array}$ & 34 & $\begin{array}{l}\text { ACSL5, FASN, MCAT, ACADSB, ACSL3, } \\
\text { PTPLB, ACOX1, PECR, ACOX3, HADH; }\end{array}$ & 19 & $\begin{array}{l}\text { miR-124-3p, miR-142-5p, } \\
\text { miR-27b-3p, miR-30a-5p, } \\
\text { miR-181a-5p }\end{array}$ & $6.23 \mathrm{e}-08$ \\
\hline $\begin{array}{l}\text { Estrogen signaling } \\
\text { pathway (hsa04915) }\end{array}$ & 73 & $\begin{array}{l}\text { ESR1, BABBR1, FOS, HBEGF, ADCY1; } \\
\text { SOS2, ATF2, ADCY7, NRAS, MAP2K2; }\end{array}$ & 30 & $\begin{array}{l}\text { miR-103a-3p, miR-148a-3p, } \\
\text { miR-27b-3p, miR-28-3p, } \\
\text { miR-532-5p; }\end{array}$ & $4.50 \mathrm{e}-06$ \\
\hline $\begin{array}{l}\text { Oocyte meiosis } \\
\text { (hsa04114) }\end{array}$ & 78 & $\begin{array}{l}\text { SLK, ESPL1, PPP1CA, FBXO5, CAMK2D, } \\
\text { PPP2R5E, SMC1A, YWHAH, ADCY1, } \\
\text { CCNB1; }\end{array}$ & 30 & $\begin{array}{l}\text { miR-92b-3p, miR-30a-5p, } \\
\text { miR-365a-3p, let-7i-5p } \\
\text { miR-708-5p; }\end{array}$ & 0.00015 \\
\hline $\begin{array}{l}\text { Endometrial cancer } \\
\text { (hsa05213) }\end{array}$ & 40 & $\begin{array}{l}\text { BRAF, GSK3B, ERBB2, SOS2, NRAS, } \\
\text { MAP2K2, APC, PIK3CB, TCF7L2, RAF1; }\end{array}$ & 27 & $\begin{array}{l}\text { miR-138-5p, miR-181b-5p, } \\
\text { miR-126-3p, miR-146a-5p, } \\
\text { miR-676-3p; }\end{array}$ & 0.00108 \\
\hline $\begin{array}{l}\text { Progesterone-mediated } \\
\text { oocyte maturation } \\
\text { (hsa04914) }\end{array}$ & 65 & $\begin{array}{l}\text { BRAF, ADCY1, CCNB1, PGR, CCNA7, } \\
\text { BUB1, FZR1, GNAI3, ANAPC2, ARAF; }\end{array}$ & 29 & $\begin{array}{l}\text { miR-592, let-7b-5p, } \\
\text { miR-124-3p, miR-181a-5p, } \\
\text { miR-30e-5p; }\end{array}$ & 0.00116 \\
\hline $\begin{array}{l}\text { Prolactin signaling } \\
\text { pathway (hsa04917) }\end{array}$ & 52 & $\begin{array}{l}\text { ESR1, PRLR, FOS, GSK3B, STAT3, } \\
\text { NFKB1, SOCS4, SOS2, CISH, JAK2; }\end{array}$ & 28 & $\begin{array}{l}\text { miR-490-3p, let-7i-5p, } \\
\text { miR-124-3p, miR-191-5p; }\end{array}$ & 0.00221 \\
\hline $\begin{array}{l}\text { Long-term depression } \\
\text { (hsa04730) }\end{array}$ & 39 & $\begin{array}{l}\text { BRAF, PRKCA, GNA12, NRAS, GNAS, } \\
\text { GNA13, PLA2G4F, GNAQ, ITPR3; }\end{array}$ & 29 & $\begin{array}{l}\text { miR-124-3p, miR-92b-3p, } \\
\text { miR-365a-3p, miR-708-5p, } \\
\text { miR-181a-5p }\end{array}$ & 0.00420 \\
\hline $\begin{array}{l}\text { Steroid biosynthesis } \\
\text { (hsa00100) }\end{array}$ & 14 & $\begin{array}{l}\text { SS5D, TM7SF2, MSMO1, DHCR24, } \\
\text { CYP51A1, SOAT1, LSS, SQLE; }\end{array}$ & 21 & $\begin{array}{l}\operatorname{miR}-30 a-5 p, \operatorname{miR}-30 b-5 p \\
\text { miR-30e-5p, miR-148a-3p; }\end{array}$ & 0.00709 \\
\hline Axon guidance (hsa04360) & 78 & $\begin{array}{l}\text { EFNB2, SEMAGA, PLXNA2, GSK3B, } \\
\text { MET, ROCK1, LICAM, FES, RHOA; }\end{array}$ & 30 & $\begin{array}{l}\text { miR-124-3p, miR-148a-3p, } \\
\text { miR-676-3p, miR-99b-5p; }\end{array}$ & 0.04447 \\
\hline
\end{tabular}

Upregulated miRNAs are in bold

system process (Supplementary file 2, 3). This implies they may underlie sex-related pain sensitivity through sex hormone and immune response-driven mechanisms; however, it requires further research. Moreover, miR320a was the most commonly identified in different types of pain, which suggests it may be a universal pain mediator. It was also reported that it may undergo sex influence [96]. Altogether, the previous results along with our study indicate it may be an especially promising biomarker to be tested.

Pathways enriched in miRNAs differentially expressed between females and males play roles in crucial neuronal processes

Among identified herein miRNA overrepresented pathways was PI3K-Akt signaling pathway (Supplementary

Table 2 Significant gene ontology terms enriched in the identified miRNAs differentially expressed in females vs. males

\begin{tabular}{|c|c|c|c|c|c|}
\hline GO term & $\begin{array}{l}\text { Number } \\
\text { of genes }\end{array}$ & Examples of genes & $\begin{array}{l}\text { Number of } \\
\text { miRNAs }\end{array}$ & Examples of miRNAs & $p$ value \\
\hline $\begin{array}{l}\text { Response to stress } \\
\text { (GO:0006950) }\end{array}$ & 1191 & $\begin{array}{l}\text { TERF2, POLR2B, VPS4A, VAPB, } \\
\text { ARPC5, NDUFS2, B2M, TAOK3, } \\
\text { E2F7, PELI1; }\end{array}$ & 27 & $\begin{array}{l}\text { let-7b-5p, miR-126-3p, miR-138-5p, } \\
\text { miR-140-3p, miR-142-5p }\end{array}$ & $<1 \mathrm{e}-325$ \\
\hline $\begin{array}{l}\text { Enzyme regulator } \\
\text { activity (GO:0030234) }\end{array}$ & 376 & $\begin{array}{l}\text { ARHGAP1, TBC1D20, TAOK3, } \\
\text { TRIB3, RGS17, PFN1, ANP32E, } \\
\text { PRLR, PKIA; }\end{array}$ & 19 & $\begin{array}{l}\text { miR-146a-5p, miR-148a-3p, miR-28-3p, } \\
\text { miR-34c-5p, miR-92b-3p; }\end{array}$ & $<1 \mathrm{e}-325$ \\
\hline $\begin{array}{l}\text { Immune system process } \\
\text { (GO:0002376) }\end{array}$ & 742 & $\begin{array}{l}\text { ARPC5, B2M, PELI1, TRIB3, } \\
\text { BRK1, IRS2, CCL2, ADAM9, } \\
\text { ACTB; }\end{array}$ & 26 & $\begin{array}{l}\text { miR-126-3p, miR-138-5p, miR-140-3p, } \\
\text { miR-142-5p, miR-146a-5p }\end{array}$ & $<1 \mathrm{e}-325$ \\
\hline $\begin{array}{l}\text { Catabolic process } \\
\text { (GO:0009056) }\end{array}$ & 1146 & $\begin{array}{l}\text { RNF41, VPS4A, ABCD4, ERLIN1, } \\
\text { YTHDC2, PPP1CA, RAB2B, RPA1; }\end{array}$ & 26 & $\begin{array}{l}\text { miR-142-5p, miR-146a-5p, miR-181a-5p, } \\
\text { miR-181b-5p, miR-185-5p; }\end{array}$ & $<1 \mathrm{e}-325$ \\
\hline $\begin{array}{l}\text { Generation of precursor } \\
\text { metabolites and energy } \\
\text { (GO:0006091) }\end{array}$ & 163 & $\begin{array}{l}\text { NDUFS2, PPP1CA, FASN, } \\
\text { PRKCA, PYGL, PFKP, COX8A, } \\
\text { ACOX1; }\end{array}$ & 14 & $\begin{array}{l}\text { let-7b-5p, let-7i-5p, miR-181b-5p, } \\
\text { miR-185-5p, miR-27b-3p; }\end{array}$ & $1.11 \mathrm{e}-16$ \\
\hline $\begin{array}{l}\text { Transcription factor } \\
\text { binding (GO:0008134) }\end{array}$ & 233 & $\begin{array}{l}\text { FHL2, TRIP6, ACTB, NACA, TCF3, } \\
\text { HIPK2, STAT3, HOXA7, PAX6; }\end{array}$ & 16 & $\begin{array}{l}\operatorname{miR}-181 b-5 p, \operatorname{miR}-27 b-3 p, \text { miR-30e-5p, } \\
\text { miR-532-5p; }\end{array}$ & $4.10 \mathrm{e}-15$ \\
\hline
\end{tabular}

Upregulated miRNAs are in bold 


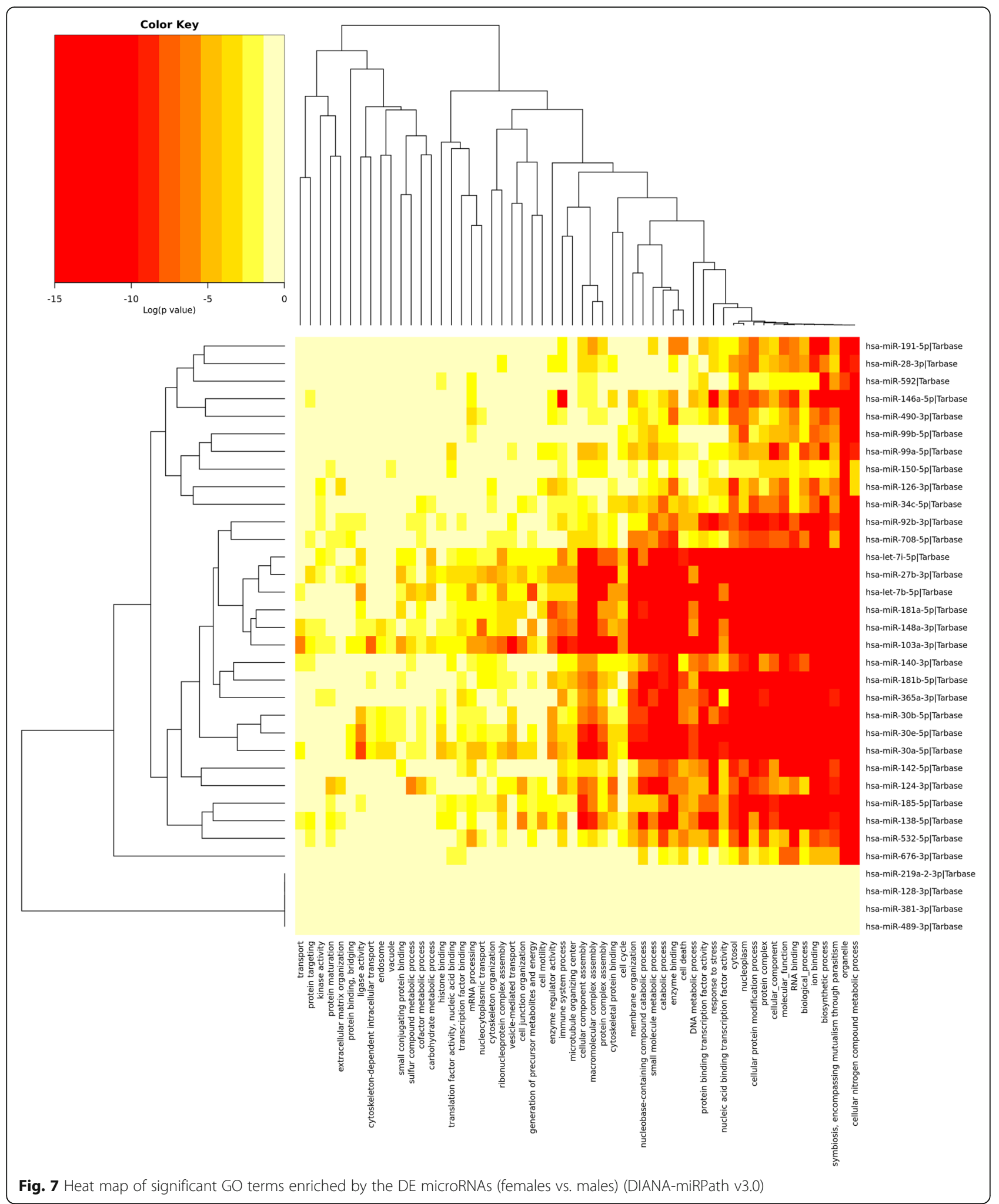

file 3). This pathway was established to be of profound significance in emotional regulation, language, behaviors, and complex cognition, while disruptions of this multifaceted interaction network were regarded as a root cause of different neuronal diseases, such as epilepsy, autism, and schizophrenia [101]. Moreover, also the components of the axon guidance pathway (Fig. 6) are being associated with schizophrenia and other psychiatric disorders 
Table 3 The correlation coefficient of RNA-seq and qRT-PCR

data

\begin{tabular}{ll}
\hline miRNA & $\mathbf{R}$ \\
\hline miR-7-5p & $0.95^{* * * *}$ \\
miR-21-5p & $0.88^{* * *}$ \\
miR-378a-3p & $0.56^{* *}$ \\
miR-20a-5p & $0.62^{* *}$ \\
miR-23a-3p & $0.36^{\mathrm{ns}}$ \\
miR-103a-3p & $0.21^{\mathrm{ns}}$ \\
miR-127-3p & $0.78^{* * *}$ \\
miR-210-3p & $0.77^{* * *}$ \\
miR-339-5p & $0.12^{\mathrm{ns}}$ \\
\hline$R$ Spearman correlation coefficient with $p$ value ${ }^{* * *} p<0.001 ; * * p<0.01 ; n s$
\end{tabular}
not significant)

[102]. When it comes to the physiological role of this pathway, it is responsible for a nervous system peculiar feature, because it directs growing axons toward their targets, which creates the complex wiring of the neuronal tissue.
Another identified key neurodevelopmental pathway was long-term depression (Fig. 4, Table 1), which is a form of synaptic plasticity-a biological process thought to contribute to memory and learning. Growing evidence supports miRNA involvement in this mechanism [103], which is in line with our results. Moreover, this form of synaptic plasticity has been investigated in terms of its involvement in chronic pain [104, 105]. Since the PAG plays a key role in the modulation and perception of pain $[8,91]$, the engagement of this pathway in mechanisms underlying the PAG-associated pain is worth further investigation. What is more, long-term depression pathway-enriched miRNAs identified in this study may provide potential candidates for such research (Supplementary file 3).

Of note, other synapse-related KEGG pathways such as GABAergic synapse, glutamatergic synapse, dopaminergic synapse, and cholinergic synapse (Supplementary file 3) were identified in this study as enriched by the detected microRNAs. These pathways are shown to be involved in the transmission of signals to and from the PAG [91]. Furthermore, estrogen signaling pathway, oocyte meiosis pathway, and prolactin signaling pathway

Table 4 Examples of miRNAs associated with neurological or neuropsychiatric diseases, identified as differentially expressed in our study

\begin{tabular}{|c|c|c|}
\hline miRNA name & Up or downregulated in females vs. males & Disease \\
\hline miR-381-3p & - & Sc [72] \\
\hline miR-34c & - & $\mathrm{AD}[75], \mathrm{PD}[76]$ \\
\hline $\operatorname{miR}-489$ & - & ASD [77], Sc [72] \\
\hline miR-320 & - & ASD [78], S [61] \\
\hline $\operatorname{miR}-27 b-3 p$ & - & S [79], AD [80], MS [60], Sc [72] \\
\hline miR-181a & - & Sc [72] \\
\hline miR-181b & - & S [81], Sc [72] \\
\hline miR-30e-5p & - & MS [60] \\
\hline miR-30a-5p & - & MS [60], Sc [71] \\
\hline $\operatorname{miR}-28-3 p$ & - & Sc [72] \\
\hline miR-30b-5p & - & MS [82], Sc [71] \\
\hline miR-185 & - & PD [83], MD [84] \\
\hline miR-150 & - & S [85], Sc [72] \\
\hline miR-191 & - & AD [86] \\
\hline miR-124a & + & $S[61]$ \\
\hline miR-128 & + & Sc [72] \\
\hline miR-126-3p & + & $S[61]$ \\
\hline miR-92a & + & Sc [71] \\
\hline miR-99a-5p & + & S [61], Sc [72] \\
\hline let-7i-5p & + & S [61] \\
\hline miR-138 & + & $S C[72]$ \\
\hline miR-148a-3p & + & MS [60], S [61] \\
\hline miR-219b-3p & + & S [61] \\
\hline
\end{tabular}

Sc schizophrenia, AD Alzheimer's disease, $P D$ Parkinson's disease, $A S D$ autism spectrum disorders, MS multiple sclerosis, $S$ stroke, $M D$ major depression 
(Fig. 4, Table 1) were statistically significantly overrepresented by the identified DE miRNAs. The enrichment of these pathways is not surprising having taken into consideration the investigated influence of miRNA-related sex differences on biological processes. What is more, prolactin, which is responsible for maternal behavior, was established to induce the activity of the PAG region, which is one of nuclei of the sociosexual and maternal brain [106].

The identification of pathways crucial for nervous tissue biology confirms the role and significance of miRNAs for the PAG physiology, with a special emphasis on those potentially taking part in mechanisms responsible for sex differences.

\section{Conclusions}

The comprehensive analysis of the miRNAome profile of the porcine PAG tissue enabled us to determine conservative miRNAs characteristic for the brain tissue, such as miR-9, -26a, and -99a-5p. Of note, this is the first study to reveal the repertoire of potentially novel sequences and isomiR signatures in the pig PAG region, which sheds some light on the multifaceted influence of miRNA expression on brain functioning and gives a stimulus for future research. Furthermore, the comparison of miRNAome profiles in terms of sex influence revealed numerous miRNAs with potential to underlie a range of processes and diseases manifested in sex-related manner. Further analysis allowed identification of biological pathways essential for neurodevelopment and neuronal functioning, as well as other molecular processes which may constitute a part of mechanisms driving sex differences. The identification of the present study miRNAs in human brain-focused studies may act as the confirmation of the obtained results, and, at the same time, as the confirmation of significant roles of miRNAs in the neurodevelopmental processes. Additional research is warranted to elucidate the exact relationships between the identified miRNAs and physiological processes being disrupted in the course of different diseases in humans in a sex-dependent manner, and, as a result, to investigate the clinical potential of those microRNAs for treatment.

\section{Perspectives and significance}

Taking into consideration the problematic access to brain tissues of patients, animal models, especially the pig with its physiological resemblance to the human, constitute potent sources to carry out such research. Therefore, obtained in this study results provide potential miRNAs and pathways to be investigated in the future research embracing the higher number of samples and the species of particular interest that is the human, to gain wider and more comprehensive view of brain and sex-driven mechanisms,.

\section{Supplementary Information}

The online version contains supplementary material available at https://doi. org/10.1186/s13293-020-00343-2.

Additional file 1. Supplementary File 1. Detailed data on the identified miRNAs. Table containing data about microRNAs detected in all investigated samples with the use of the UEA sRNA Workbench software. "NA" in the "miRNA name" column denotes potentially novel miRNAs identified in this study, which additionally are bolded.

Additional file 2. Supplementary File 2. Results of the differential expression analysis between females and males using the DESeq2 algorithm ( $p$ value $\leq 0.05$ ). "log2FoldChange" - the binary logarithm of the Fold Change parameter; "NA" in the miRNA name column stands for potentially novel microRNAs identified in this study.

Additional file 3. Supplementary File 3. List of KEGG pathways enriched by the detected differentially expressed in females microRNAs ( $p$ value $\leq 0.05$ ).

Additional file 4. Supplementary File 4. List of GO terms enriched by the identified differentially expressed in females microRNAs ( $p$ value $\leq 0.05$ ).

\section{Abbreviations}

PAG: Periaqueductal grey; DE miRNAs: Differentially expressed microRNAs; miR: MicroRNA; FDR: False discovery rate; KEGG: Kyoto Encyclopedia of Genes and Genomes; GO: Gene ontology; RT-qPCR: Reverse transcription quantitative polymerase chain reaction; NTC: Non-template control; GEO database: Gene Expression Omnibus database; NGS: Next-generation sequencing; RISC: RNA-induced silencing complex; CNS: Central nervous system; DDX3X: DEAD-Box Helicase 3 X-Linked; ATP: Adenosine triphosphate; IGF1R: Insulin-like growth factor-1 receptor; AGO1: Argonaute1;

AGO2: Argonaute2; SERPINE1: Serpin family E member 1; MEF2D: Myocyte enhancer factor 2D; PI3K-Akt: Phosphatidylinositol-3-kinase and protein kinase B; Sc: Schizophrenia; AD: Alzheimer's disease; PD: Parkinson's disease; ASD: Autism spectrum disorders; MS: Multiple Sclerosis; S: Stroke; MD: Major depression; GABA: Gamma-Aminobutyric acid

\section{Acknowledgements}

Not applicable.

\section{Availability of supporting data}

The datasets generated and analyzed during the current study are available in the NCBI GEO database, under the following number: GSE148302.

\section{Authors' contributions}

KPT conceived and designed the experiment with the input of $\mathrm{MO}$ and MBP KPT and AG performed the experiments; KPT, TS, and MO analyzed the data; $\mathrm{KPT}, \mathrm{MO}$, and MBP wrote and revised the paper. All authors read and approved the final manuscript.

\section{Funding}

The study was supported by the National Science Center in Poland (project no. 2015/19/N/NZ9/00608).

Ethics approval and consent to participate Not applicable.

\section{Consent for publication}

The authors consent for the Biology of Sex Differences to publish this material.

\section{Competing interests}

The authors declare that they have no competing interests.

\section{Author details}

${ }^{1}$ Department of Animal Molecular Biology, National Research Institute of Animal Production, Krakowska 1, 32-083, Balice, Kraków, Poland. ${ }^{2}$ Center for Experimental and Innovative Medicine, University of Agriculture in Kraków, Rędzina 1c, 30-248 Kraków, Poland. ³Department of Animal Reproduction, 
Anatomy and Genomics, University of Agriculture in Kraków, al. Mickiewicza 24/28, 30-059 Kraków, Poland.

\section{Received: 14 August 2020 Accepted: 17 November 2020 Published online: 11 December 2020}

\section{References}

1. Nabuurs MJ. Weaning piglets as a model for studying pathophysiology of diarrhoea. Vet Q. 1998;20(Suppl 3):S42-S5.

2. Brambilla G, Cantafora A. Metabolic and cardiovascular disorders in highly inbred lines for intensive pig farming: how animal welfare evaluation could improve the basic knowledge of human obesity. Ann Ist Super Sanita. 2004; 40:241-4.

3. Sartor RB. Probiotic therapy of intestinal inflammation and infections. Curr Opin Gastroenterol. 2005;21(1):44-50.

4. Lind NM, Moustgaard A, Jelsing J, Vajta G, Cumming P, Hansen AK. The use of pigs in neuroscience: modeling brain disorders. Neurosci Biobehav Rev. 2007:31:728-51.

5. Rathner JA, Morrison SF. Rostral ventromedial periaqueductal gray: a source of inhibition of the sympathetic outflow to brown adipose tissue. Brain Res. 2006;1077(1):99-107

6. Farkas $\mathrm{E}$, Jansen $\mathrm{AS}$, Loewy $\mathrm{AD}$. Periaqueductal gray matter input to cardiac related sympathetic premotor neurons. Brain Res. 1998;792(2):179-92.

7. Mouton $L$, Holstege $G$. The periaqueductal gray in the cat projects to lamina-Viii and the medial part of lamina-vii throughout the length of the spinal-cord. Exp Brain Res. 1994;101(2):253-64

8. Budai D, Harasawa I, Fields HL. Midbrain periaqueductal gray (PAG) inhibits nociceptive inputs to sacral dorsal horn nociceptive neurons through alpha(2)-adrenergic receptors. J Neurophysiol. 1998;80(5):2244-54.

9. Deng H, Xiao X, Wang Z. Periaqueductal Gray neuronal activities underlie different aspects of defensive behaviors. J Neurosci. 2016;36(29):7580-8.

10. Bartels A, Zeki S. The neural correlates of maternal and romantic love. Neurolmage. 2004;21(3):1155-66.

11. Weiller C, May A, Limmroth V, Juptner M, Kaube H, Schayck RV, Coenen HH, Diener HC. Brain stem activation in spontaneous human migraine attacks. Nat Med. 1995;1(7):658-60

12. Sakakibara R, Hattori T, Yasuda K, Yamanishi T, Tojo M, Mori M. Micturitional disturbance in Wernicke's encephalopathy. Neurourol Urodyn. 1997;16(2): $111-5$.

13. Papadopoulou A, Naegelin Y, Weier K, Amann M, Hirsch J, von Felten S, Yaldizli O, Sprenger T, Radue EW, Kappos L, Gass A. MRI characteristics of periaqueductal lesions in multiple sclerosis. Mult Scler Relat Disord. 2014; 3(4):542-51.

14. Liao PW, Liu SP, Yu HJ, Yeong-Shiau P, Ho CH. Acute urinary retention after brainstem infarction. Incont Pelvic Floor Dysfunct. 2013;7:10-1.

15. Cho YS, Ko IG, Kim CJ, Kim KH. A novel intracerebral hemorrhage-induced rat model of neurogenic voiding dysfunction: analysis of lower urinary tract function. Mol Med Rep. 2015;12(2):2563-9.

16. Sempere LF, Freemantle S, Pitha-Rowe I, Moss E, Dmitrovsky E, Ambros V. Expression profiling of mammalian microRNAs uncovers a subset of brain expressed microRNAs with possible roles in murine and human neuronal differentiation. Genome Biol. 2004:5:R13.

17. Meister G, Tuschl T. Mechanisms of gene silencing by double-stranded RNA. Nature. 2004:431:343-9.

18. Chen CZ, Lodish HF. MicroRNAs as regulators of mammalian hematopoiesis. Semin Immunol. 2005;1:155-65.

19. Lu J, Qian J, Chen F, Tang XZ, Li C, Cardoso W. Differential expression of components of the microRNA machinery during mouse organogenesis. Biochem Biophys Res Commun. 2005;334:319-23.

20. Yi R, O'Carroll D, Pasolli HA, Zhang Z, Dietrich FS, Tarakhovsky A, Fuchs E. Morphogenesis in skin is governed by discrete sets of differentially expressed microRNAs. Nat Gene. 2006;38:356-62.

21. Giraldez AJ, Cinalli RM, Glasner ME, Enright AJ, Thomson JM, Baskerville S, Hammond SM, Bartel DP, Schier AF. MicroRNAs regulate brain morphogenesis in zebrafish. Science. 2005;308:833-8.

22. Deng S, Calin GA, Croce CM, Coukos G, Zhang L. Mechanisms of microRNA deregulation in human cancer. Cell Cycle. 2008;7(17):2643-6.

23. Volinia S, Calin GA, Liu C-G, Ambs S, Cimmino A, Petrocca F, Visone R, lorio M, Roldo C, Ferracin M, Prueitt RL, Yanaihara N, Lanza G, Scarpa A, Vecchione A, Negrini M, Harris CC, Croce CM. A microRNA expression signature of human solid tumors defines cancer gene targets. Proc Nat Acad Sci USA. 2006:103:2257-61.

24. Pedroza-Torres A, López-Urrutia E, García-Castillo V, Jacobo-Herrera N, Herrera LA, Peralta-Zaragoza O, López-Camarillo C, De Leon DC, FernándezRetana J, Cerna-Cortés JF, Pérez-Plasencia C. MicroRNAs in cervical cancer: Evidences for a miRNA profile deregulated by HPV and its impact on radioresistance. Molecules. 2014;19:6263-81.

25. He L, Hannon GJ. MicroRNAs: small RNAs with a big role in gene regulation. Nat Rev Genet. 2004:5:522-31.

26. Lu C, Tej SS, Luo S, Haudenschild CD, Meyers BC, Green PJ. Elucidation of the small RNA component of the transcriptome. Science. 2005;309:1567-9.

27. Chin $L J$, Slack FJ. A truth serum for cancer-microRNAs have major potential as cancer biomarkers. Cell Res. 2008;18(10):983-4.

28. Cho WC. MicroRNAs: potential biomarkers for cancer diagnosis, prognosis and targets for therapy. Int J Biochem Cell Biol. 2010;42(8):1273-81.

29. Gao FB. Posttranscriptional control of neuronal development by microRNA networks. Trends Neurosci. 2008;31:20-6.

30. Krichevsky AM, King KS, Donahue CP, Khrapko K, Kosik KS. A microRNA array reveals extensive regulation of microRNAs during brain development. RNA. 2003;9:1274-81.

31. Miska EA, Alvarez-Saavedra E, Townsend M, Yoshii A, Sestan N, Rakic P, Constantine-Paton M, Horvitz HR. Microarray analysis of microRNA expression in the developing mammalian brain. Genome Biol. 2004;5:R68.

32. Podolska A, Kaczkowski B, Kamp Busk P, Søkilde R, Litman T, Fredholm M, Cirera S. MicroRNA expression profiling of the porcine developing brain. PloS one. 2011;6(1):e14494.

33. Khaitovich P, Muetzel B, She X, Lachmann M, Hellmann I, Dietzsch J, Steigele S, Do HH, Weiss G, Enard W, Heissig F, Arendt T, Nieselt-Struwe K, Eichler EE, Pääbo S. Regional patterns of gene expression in human and chimpanzee brains. Genome Res. 2004:14(8):1462-73.

34. Olsen L, Klausen M, Helboe L, Nielsen FC, Werge T. MicroRNAs show mutually exclusive expression patterns in the brain of adult male rats. PLOS ONE. 2009;4(10):e7225

35. Linnman C, Beucke JC, Jensen KB, Gollub RL, Kong J. Sex similarities and differences in pain-related periaqueductal gray connectivity. Pain. 2012; 153(2):444-54.

36. Nasser SA, Afify EA. Sex differences in pain and opioid mediated antinociception: Modulatory role of gonadal hormones. Life Sciences. 2019; 237:116926.

37. Herson PS, Palmateer J, Hurn PD. Biological sex and mechanisms of ischemic brain injury. Transl. Stroke Res. 2013;4(4):413-9.

38. Andrews S. FastQC: a quality control tool for high throughput sequence data. 2010 (http://www.bioinformatics.babraham.ac.uk/projects/fastqc)

39. Stocks MB, Moxon S, Mapleson D, Woolfenden HC, Mohorianu I, Folkes L, Schwach F, Dalmay T, Moulton V. The UEA sRNA workbench: a suite of tools for analysing and visualizing next generation sequencing microRNA and small RNA datasets. Bioinformatics 2012;28:2059-2061.

40. Ropka-Molik K, Pawlina-Tyszko K, Żukowski K, Piórkowska K, Żak G, Gurgul A, Derebecka N, Wesoły J. Examining the genetic background of porcine muscle growth and development based on transcriptome and miRNAome data. Int. J. Mol. 2018:19(4):1208.

41. Griffiths-Jones S, Grocock RJ, van Dongen S, Bateman A, Enright AJ. miRBase: microRNA sequences, targets and gene nomenclature. Nucleic Acids Res. 2006;34(Database issue):D140-D4.

42. Griffiths-Jones S, Sainim HK, van Dongenm S, Enrightm AJ. miRBase: tools for microRNA genomics. Nucleic Acids Res. 2008;36(Database issue):D154-D8

43. The RNAcentral Consortium. RNAcentral: a hub of information for noncoding RNA sequences. Nucleic Acids Res. 2019:47(D1):D221-D9.

44. Urgese G, Paciello G. Acquaviva A. Ficarra E. isomiR-SEA: an RNA-Seq analysis tool for miRNAs/isomiRs expression level profiling and miRNAmRNA interaction sites evaluation. BMC Bioinformatics. 2016;17:148

45. Love MI, Huber W, Anders S. Moderated estimation of fold change and dispersion for RNA-seq data with DESeq2. Genome Biol. 2014;15:550.

46. Kolde R. pheatmap: Pretty Heatmaps. R package version 1.0.12. 2019 https:// CRAN.R-project.org/package=pheatmap.

47. Core Team R. R: A language and environment for statistical computing. In: R Foundation for Statistical Computing. Vienna: Austria. URL; 2019. https:// www.R-project.org/.

48. Fan Y, Siklenka K, Arora SK, Ribeiro P. Kimmins S. Xia J. miRNet - dissecting miRNA-target interactions and functional associations through networkbased visual analysis. Nucleic Acids Res. 2016;44:W135-41. 
49. Fan Y, Xia J. miRNet-functional analysis and visual exploration of miRNAtarget interactions in a network context. Methods Mol Biol. 2018;1819:215-33.

50. Vlachos IS, Zagganas K, Paraskevopoulou MD, Georgakilas G, Karagkouni D, Vergoulis T, Dalamagas T, Hatzigeorgiou AG. DIANA-miRPath v3.0: deciphering microRNA function with experimental support. Nucleic Acids Res. 2015;43(W1):W460-W6.

51. Andersen $\mathrm{CL}$, Jensen $J$, Ørntoft TF. Normalization of real-time quantitative reverse transcription-PCR data: a model-based variance estimation approach to identify genes suited for normalization, applied to bladder and colon cancer data sets. Cancer Res. 2004;64:5245-50.

52. Pfaffl MW. A new mathematical model for relative quantification in real-time RT-PCR. Nucleic Acids Res. 2001;29(9):e45.

53. Forero DA, van der Ven K, Callaerts P, Del-Favero J. miRNA genes and the brain: implications for psychiatric disordersa. Hum. Mutat. 2010;31:1195-204.

54. Wojcicka A, Swierniak M, Kornasiewicz O, Gierlikowski W, Maciag M, Kolanowska M, Kotlarek M, Gornicka B, Koperski L, Niewiński G, Krawczyk M, Jazdzewski K. Next generation sequencing reveals microRNA isoforms in liver cirrhosis and hepatocellular carcinoma. Int. J. Biochem. Cell Biol. 2014; 53:208-17.

55. Pawlina K, Gurgul A, Szmatoła T, Koch C, Mählmann K, Witkowski M, BugnoPoniewierska M. Comprehensive characteristics of microRNA expression profile of equine sarcoids. Biochimie. 2017;137:20-8.

56. Liu Y, Zhang J, Han R, Liu H, Sun D, Liu X. Downregulation of serum brain specific microRNA is associated with inflammation and infarct volume in acute ischemic stroke. J. Clin. Neurosci. 2015;22(2):291-5.

57. Liang Y, Ridzon D, Wong L, Chen C. Characterization of microRNA expression profiles in normal human tissues. BMC Genomics. 2007;8:166.

58. Sim SE, Lim CS, Kim JI, Seo D, Chun H, Yu NK, Lee J, Kang SJ, Ko HG, Choi JH, Kim T, Jang EH, Han J, Bak MS, Park JE, Jang DJ, Baek D, Lee YS, Kaang BK. The brain-enriched MicroRNA miR-9-3p regulates synaptic plasticity and memory. J. Neurosci. 2016;36(33):8641-52.

59. Meder B, Backes C, Haas J, Leidinger P, Stähler C, Großmann T, Vogel B, Frese K, Giannitsis E, Katus HA, Meese E, Keller A. Influence of the confounding factors age and sex on MicroRNA profiles from peripheral blood. Clin. Chem. 2014;60(9):1200-8.

60. Muñoz-Culla M, Irizar H, Sáenz-Cuesta M, Castillo-Triviño T, Osorio-Querejeta I, Sepúlveda L, López de Munain A, Olascoaga J, Otaegui D. SncRNA (microRNA\&snoRNA) opposite expression pattern found in multiple sclerosis relapse and remission is sex dependent. Sci. Rep. 2016;6:20126.

61. Khoshnam SE, Winlow W, Farbood Y, Moghaddam HF, Farzaneh M. Emerging roles of microRNAs in ischemic stroke: as possible therapeutic agents. J. Stroke. 2017;19(2):166-87.

62. Hueng DY, Tsai WC, Chiou HY, Feng SW, Lin C, Li YF, Huang LC, Lin MH. DDX3X biomarker correlates with poor survival in human gliomas. Int. J. Mol. 2015;16(7):15578-91.

63. Nieto Guil AF, Oksdath M, Weiss LA, Grassi DJ, Sosa L, Nieto M, Quiroga S. IGF-1 receptor regulates dynamic changes in neuronal polarity during cerebral cortical migration. Sci. Rep. 2017;7(1):7703.

64. Jin J, Ravindran P, Di Meo D, Püschel AW. Igf1R/InsR function is required for axon extension and corpus callosum formation. PloS one. 2019;14(7): e0219362.

65. Lewkowicz P, Cwiklińska H, Mycko MP, Cichalewska M, Domowicz M, Lewkowicz N, Jurewicz A, Selmaj KW. Dysregulated RNA-induced silencing complex (RISC) assembly within CNS corresponds with abnormal miRNA expression during autoimmune demyelination. J. Neurosci. 2015;35(19): 7521-37.

66. Seker F, Cingoz A, Sur-Erdem I, Erguder N, Erkent A, Uyulur F, Esai Selvan M, Gümüş ZH, Gönen M, Bayraktar H, Wakimoto H, Bagci-Onder T. Identification of SERPINE1 as a regulator of glioblastoma cell dispersal with transcriptome profiling. Cancers. 2019;11(11):1651.

67. Kutz SM, Higgins CE, Higgins PJ. Novel combinatorial therapeutic targeting of PAl-1 (SERPINE1) gene expression in Alzheimer's disease. Mol. Med. Ther. 2012;1(2):106.

68. Rashid AJ, Cole CJ, Josselyn SA. Emerging roles for MEF2 transcription factors in memory. Genes Brain Behav. 2014;13:118-25.

69. Assali A, Harrington AJ, Cowan CW. Emerging roles for MEF2 in brain development and mental disorders. Curr. Opin. Neurobiol. 2019;59:49-58.

70. Miller $\mathrm{BH}$, Wahlestedt C. MicroRNA dysregulation in psychiatric disease. Brain Res. 2010;1338:89-99.

71. Perkins DO, Jeffries CD, Jarskog LF, Thomson JM, Woods K, Newman MA, Parker JS, Jin J, Hammond SM. microRNA expression in the prefrontal cortex of individuals with schizophrenia and schizoaffective disorder. Genome Biol. 2007;8(2):R27.

72. Beveridge NJ, Gardiner E, Carroll AP, Tooney PA, Cairns MJ. Schizophrenia is associated with an increase in cortical microRNA biogenesis. Mol. Psychiatr. 2010;15(12):1176-89.

73. Panksepp J. The neural nature of the core SELF: implications for understanding schizophrenia. In: Kircher T, David A, editors. The self in neuroscience and psychiatry, Cambridge University Press, vol. 2003; 2003. p. 197-213.

74. Koropouli E, Melanitis N, Dimitriou Vl, Grigoriou A, Karavasilis E, Nikita KS, Tzavellas E, Paparrigopoulos T. New-onset psychosis associated with a lesion localized in the rostral tectum: insights into pathway-specific connectivity disrupted in psychosis. Schizophrenia Bulletin. 2020;46(5):1296-305.

75. Shi Z, Zhang $K$, Zhou H, Jiang L, Xie B, Wang R, Xia W, Yin Y, Gao Z, Cui D, Zhang R, Xu S. Increased miR-34c mediates synaptic deficits by targeting synaptotagmin 1 through ROS-JNK-p53 pathway in Alzheimer's Disease. Aging Cell. 2020;19(3):e13125.

76. Kabaria S, Choi DC, Chaudhuri AD, Mouradian MM, Junn E. Inhibition of miR-34b and miR-34c enhances a-synuclein expression in Parkinson's disease. FEBS Lett. 2015;589(3):319-25.

77. Mundalil Vasu M, Anitha A, Thanseem I, Suzuki K, Yamada K, Takahashi T, Wakuda T, Iwata K, Tsujii M, Sugiyama T, Mori N. Serum microRNA profiles in children with autism. Mol Autism. 2014:5:40.

78. Stamova B, Ander BP, Barger N, Sharp FR, Schumann CM. Specific regional and age-related small noncoding RNA expression patterns within superior temporal gyrus of typical human brains are less distinct in autism brains. J Child Neurol. 2015;30(14):1930-46.

79. Cheng X, Kan P, Ma Z, Wang Y, Song W, Huang C, Zhang B. Exploring the potential value of miR-148b-3p, miR-151b and miR-27b-3p as biomarkers in acute ischemic stroke. Biosci Rep. 2018;38(6):BSR20181033.

80. Agostini S, Mancuso R, Liuzzo G, Bolognesi E, Costa AS, Bianchi A, Clerici M. Serum miRNAs expression and SNAP-25 genotype in Alzheimer's disease. Front Aging Neurosci. 2019;11:52.

81. Han X, Zheng Z, Wang C, Wang L. Association between MEG3/miR-181b polymorphisms and risk of ischemic stroke. Lipids Health Dis. 2018;17(1):292.

82. Ebrahimkhani S, Vafaee F, Young PE, Hur SSJ, Hawke S, Devenney E, Beadnall H, Barnett MH, Suter CM, Buckland ME. Exosomal microRNA signatures in multiple sclerosis reflect disease status. Sci Rep. 2017;7(1):14293.

83. Rahimmi A, Peluso I, Rajabi A, Hassanzadeh K. miR-185 and SEPT5 genes may contribute to Parkinson's disease pathophysiology. Oxid Med Cell Longev. 2019;2019:5019815.

84. Serafini G, Pompili M, Hansen KF, Obrietan K, Dwivedi Y, Shomron N, Girardi $P$. The involvement of microRNAs in major depression, suicidal behavior, and related disorders: a focus on miR-185 and miR-491-3p. Cell Mol Neurobiol. 2014;34(1):17-30.

85. Lv H, Li J, Che YQ. MicroRNA-150 contributes to ischemic stroke through its effect on cerebral cortical neuron survival and function by inhibiting ERK1/2 axis via Mal. J Cell Physiol. 2019;234(2):1477-90.

86. Hong H, Li Y, Su B. Identification of circulating miR-125b as a potential biomarker of Alzheimer's disease in APP/PS1 Transgenic Mouse. J Alzheimers Dis. 2017;9(4):1449-58.

87. Aleman A, Kahn RS, Selten JP. Sex differences in the risk of schizophrenia: evidence from meta-analysis. Arch Gen Psychiatry. 2003;60(6):565-71.

88. McGrath J, Saha S, Chant D, Welham J. Schizophrenia: a concise overview of incidence, prevalence, and mortality. Epidemiol Rev. 2008;30:67-76.

89. Abel KM, Drake R, Goldstein JM. Sex differences in schizophrenia. Int Rev Psychiatry. 2010;22(5):417-28.

90. Li R, Ma X, Wang G, Yang J, Wang C. Why sex differences in schizophrenia? Transl. Neurosci. 2016;1(1):37-42.

91. Mokhtar M, Singh P. Neuroanatomy, Periaqueductal Gray. [Updated 2020 Jul 31]. In: StatPearls [Internet]. Treasure Island (FL): StatPearls Publishing; 2020 Jan-. Available from: https://www.ncbi.nlm.nih.gov/books/NBK554391/.

92. Orlova IA, Alexander GM, Qureshi RA, Sacan A, Graziano A, Barrett JE, Schwartzman RJ, Ajit SK. MicroRNA modulation in complex regional pain syndrome. J Transl Med. 2011;10(9):195.

93. Bjersing $J$, Bokarewa MI, Mannerkorpi K. Profile of circulating microRNAs in fibromyalgia and their relation to symptom severity: an exploratory study. Rheumatol Int. 2015:35(4):635-42.

94. Tafuri E, Santovito D, de Nardis V, Marcantonio P, Paganelli C, Affaitati G, Bucci M, Mezzetti A, Giamberardino MA, Cipollone F. MicroRNA profiling in migraine without aura: pilot study. Ann Med. 2015;47(6):468-73. 
95. Andersen HH, Duroux M, Gazerani P. Serum MicroRNA signatures in migraineurs during attacks and in pain-free periods. Mol Neurobiol. 2016; 53(3):1494-500.

96. Linnstaedt SD, Riker KD, Walker MG, Nyland JE, Zimny E, Lewandowski C Hendry PL, Damiron K, Pearson K, Velilla MA, Jones J, Swor RA, Domeier R, McLean SA. MicroRNA 320a predicts chronic axial and widespread pain development following motor vehicle collision in a stress-dependent manner. J Orthop Sports Phys Ther. 2016;46(10):911-9.

97. Leinders $\mathrm{M}$, Üçeyler $\mathrm{N}$, Thomann A, Sommer C. Aberrant microRNA expression in patients with painful peripheral neuropathies. J Neurol Sci. 2017;15(380):242-9.

98. Cheng CY, Chen SP, Liao YC, Fuh JL, Wang YF, Wang SJ. Elevated circulating endothelial-specific microRNAs in migraine patients: a pilot study. Cephalalgia. 2018;38(9):1585-91.

99. Dayer CF, Luthi F, Le Carre' J, Vuistiner P, Terrier P, Benaim C, Giacobino JP, Léger B. Differences in the miRNA signatures of chronic musculoskeletal pain patients from neuropathic or nociceptive origins. PLOS ONE 2019;14(7): e0219311.

100. Tavares-Ferreira D, Lawless N, Bird EV, Atkins S, Collier D, Sher E, Malki K, Lambert DW, Boissonade FM. Correlation of miRNA expression with intensity of neuropathic pain in man. Mol Pain. 2019;15:1744806919860323.

101. Wang L, Zhou K, Fu Z, Yu D, Huang H, Zang X, Mo X. Brain development and Akt signaling: the crossroads of signaling pathway and neurodevelopmental diseases. J. Mol. Neurosci. 2016;61:379-84.

102. Vosberg DE, Leyton M, Flores C. The Netrin-1/DCC guidance system: dopamine pathway maturation and psychiatric disorders emerging in adolescence. Mol Psychiatry. 2020;25:297-307.

103. Ceman S, Saugstad J. MicroRNAs: meta-controllers of gene expression in synaptic activity emerge as genetic and diagnostic markers of human disease. Pharmacol. Therapeut. 2011;130(1):26-37.

104. Sandkühler J. Long-term potentiation and long-term depression in the spinal cord. In: Schmidt R., Willis W. (eds). Encyclopedia of Pain. Springer, Berlin, Heidelberg; 2007. DOl. https://doi.org/10.1007/978-3-642-28753-4_ 2207

105. Kim HY, Jun J, Wang J, Bittar A, Chung K, Chung JM. Induction of long-term potentiation and long-term depression is cell-type specific in the spinal cord. PAIN. 2015;156(4):618-25.

106. Salais-López H, Lanuza E, Agustín-Pavón C. Martínez-García F. Tuning the brain for motherhood: prolactin-like central signalling in virgin, pregnant, and lactating female mice. Brain Struct Funct 2017;222:895-921.

\section{Publisher's Note}

Springer Nature remains neutral with regard to jurisdictional claims in published maps and institutional affiliations.

Ready to submit your research? Choose BMC and benefit from:

- fast, convenient online submission

- thorough peer review by experienced researchers in your field

- rapid publication on acceptance

- support for research data, including large and complex data types

- gold Open Access which fosters wider collaboration and increased citations

- maximum visibility for your research: over $100 \mathrm{M}$ website views per year

At BMC, research is always in progress.

Learn more biomedcentral.com/submissions 